ORIGINAL ARTICLE

\title{
Seatbelt legislation in Japan: high risk driver mortality and seatbelt use
}

\author{
S Nakahara, M Ichikawa, S Wakai
}

Injury Prevention 2003;9:29-32

\begin{abstract}
Objectives: To clarify why seatbelt legislation did not achieve the expected reduction in mortality in Japan.

Location and background: Seatbelt legislation was enacted in Japan in September 1985 and penalties were introduced in November 1986.

Methods: The driver deaths per vehicle $\mathrm{km}$ traveled (D/VKT) were calculated to adjust for changes in traffic volume. Decreases in D/VKT were compared with the reduction expected after legislation. The association between percentage changes of driver D/VKT, seatbelt use rate, and seatbelt non-use rate were explored. Deaths of passengers, pedestrians, and cyclists were also examined. Mortality data were obtained from vital statistics, traffic volume figures from the Ministry of Land, Infrastructure, and Transport, and seatbelt use rates from the National Police Agency.

Results: Although the decrease in D/VKT after the law was enforced was larger than the absolute number of deaths, it was far less than predicted. The percentage decrease in seatbelt non-use rate showed the strongest correlation with the percentage decrease in driver mortality. Mortality did not increase among other road users after the law was enacted.

Conclusion: Accurate evaluation of the effect of seatbelt legislation must take into account changes in traffic volume. The selective recruitment hypothesis - that high risk drivers were less responsive to seatbelt legislation-fits well with the findings. There was no conclusive evidence supporting risk compensation - that is, an increase in injuries among other road users.
\end{abstract}

See end of article for authors' affiliations

Correspondence to: Dr Shinji Nakahara, Department of International Community Health, Graduate School of Medicine, University of Tokyo, 7-3-1 Hongo, Bunkyo-ku, Tokyo

113-0033, Japan:

shinji@m.u-tokyo.ac.jp
$\mathrm{D}$ espite the fact that proper seatbelt use can significantly reduce motor vehicle occupant mortality in crashes, ${ }^{12}$ seatbelt legislation appeared to have been less effective than predicted..$^{3}$ Some studies have even documented a complete lack of discernible reductions in deaths or serious injuries after such laws. ${ }^{5-9}$ This led us to consider the risk compensation hypothesis: that because belted drivers feel safer they may drive with less care, thereby offsetting the benefit of wearing seatbelts and increasing injuries among road users.

However, different explanations may also apply. For example, selective recruitment may result in high risk drivers being less likely to comply with seatbelt laws. ${ }^{10-12}$ The rapid increase in seatbelt use immediately after the implementation of legislation would not achieve the expected results if its main effect was restricted to low risk drivers. If this theory is correct, driver mortality should be more responsive to behavior change among high risk drivers who are less likely to use seatbelts. Therefore, to accurately evaluate the effects of seatbelt legislation it is important to consider changes in seatbelt use, especially among less compliant drivers. However, most previous evaluation studies have not taken seatbelt use rates into account. ${ }^{36-8}{ }^{13-18}$ One study in the United States indicated that the selective recruitment model was consistent with the changes in mortality and morbidity observed immediately after the implementation of seatbelt legislation but this was a very short term investigation. ${ }^{12}$

In addition, the rapid increase in vehicle $\mathrm{km}$ traveled (VKT) in the 1980s might have increased the risk of occupant injury. While it is certain that drivers' exposure to risk increases in proportion to VKT, this has not been considered in previous studies comparing casualty numbers. ${ }^{36813-15}$ Some analyses have used case fatality rates as an indicator to avoid the influence of VKT increases. ${ }^{716}$ But under-reporting of morbidity data, especially police data, might have undermined the reliability of these results.

As only a few studies considered both belt use rates and traffic volume, ${ }^{19} 20$ but not selective recruitment, we hypoth- esized that selective recruitment and rapid VKT increases were a possible explanation for the seeming ineffective seatbelt legislation. Belt use for front seat occupants became compulsory in September 1985, and penalties were introduced in November 1986. This study, therefore, investigated the relationship between changes in the mortality rate and seatbelt non-use after taking account of changes in VKT. We also examined the effect of the legislation on other road users who were not protected by seatbelts to see if risk compensation followed the legislation.

\section{METHODS}

Data on the mortality of motor vehicle drivers (International Classification of Diseases (9th revision) E code 810-819.0), car passengers (E810-819.1), cyclists (E810-819.6), and pedestrians (E810-819.7) between 1979 and 1994 were obtained from vital statistics compiled by the Ministry of Health, Labour and Welfare of Japan. We did not use police records because these consider a death to have been related to a crash only if it occurred within 24 hours after the event.

Estimates of VKT were obtained from the Ministry of Land, Infrastructure and Transport based on questionnaires sent to systematically selected owners of registered motor vehicles. Seatbelt use data were provided by the National Police Agency, which observes belt use rates during spring and autumn traffic safety campaigns. Passenger belt use rates included only front seat passengers.

In order to adjust for rapid VKT increase, we calculated deaths per one billion VKT (D/VKT). The decrease in both the absolute number of driver deaths and driver D/VKT after seatbelt legislation were compared with the maximum expected reduction based on the estimation that proper belt use would reduce crash mortality by $40 \%^{1}$ and the assumption that all drivers had an equal risk of crashing.

In addition, we investigated correlations between seatbelt use rates and driver D/VKT, annual percentage point 


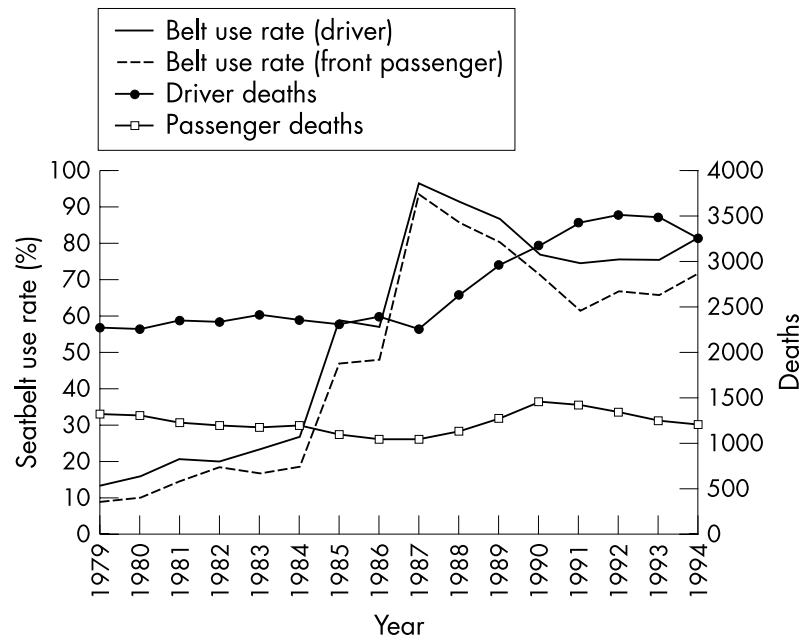

Figure 1 Trends of seatbelt use rates and deaths in Japan (1979-94). Seatbelt use became compulsory in September 1985, and penalties for violation were introduced in November 1986.

differences in seatbelt use rates and annual differences in D/VKT, annual percentage changes in belt use rates and annual percentage changes in $\mathrm{D} / \mathrm{VKT}$, and annual percentage changes in belt non-use rates and annual percentage changes in D/VKT. Variation in non-use rates was included in the analyses as it was considered to be an indicator of behavior change among drivers who were less compliant with the legislation.

Since seatbelt use rates were very low before 1983, and changes in belt use were relatively small, we predicted that few high risk drivers would have used seatbelts during that period. Therefore, our analyses were confined to 1983-94. To minimize long term trends we used year-to-year differences, while percentage changes were calculated to adjust for different baseline values of mortality and belt use rates between years.

We also examined the relationship between belt use and mortality rates for other road users. Passenger mortality included both front and rear seat passengers because position specific data were not available. As the age composition of the Japanese population changed during the study period, we used age specific mortality of child pedestrians (aged 0-4 years), cyclists (5-14 years), and car passengers ( $0-4$ years). Pearson's correlation coefficients were used to indicate associations.

\section{RESULTS}

Driver seatbelt use rates increased from $26.7 \%$ to $58.8 \%$ in 1985 after the enactment of the seatbelt legislation, and rose again from $56.8 \%$ to $96.5 \%$ in 1987 after the introduction of penalties (fig l). Driver deaths decreased by $2.0 \%$ in 1985 and by $5.2 \%$ in 1987 and over the same years driver D/VKT declined by $5.0 \%$ and $8.6 \%$, respectively (not shown). This represents $34.7 \%$ of the expected reduction in 1985 and $42.0 \%$ in 1987. Although motor vehicle passenger deaths decreased between 1984 and 1987, a period during which passenger belt use increased rapidly, there was no clear correlation between front seat passenger belt use rates and passenger deaths.

The correlation coefficient between driver seatbelt use rate and $\mathrm{D} / \mathrm{VKT}$ was low $(r=-0.140, \mathrm{p}=0.660)$. In contrast, the correlation between the annual percentage point differences in belt use rates and the annual differences of D/VKT was large and significant $(r=-0.685, \mathrm{p}=0.002)$. Although the correlation between percentage change of belt use rate and percentage change of D/VKT was relatively high, it was not statistically significant $(r=-0.560, \mathrm{p}=0.073)$. However, the

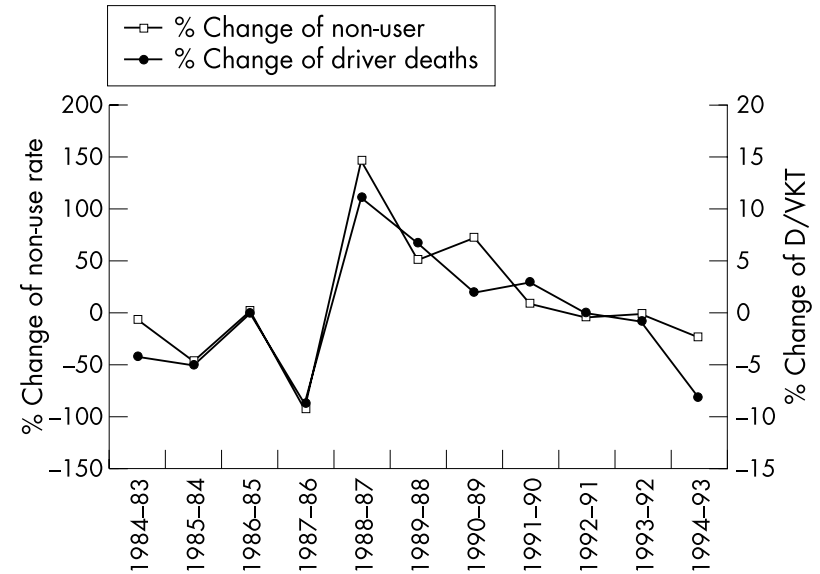

Figure 2 Percentage change of seatbelt non-use rate and driver deaths per one billion vehicle $\mathrm{km}$ traveled (D/VKT) in Japan (1983-94). Seatbelt use became compulsory in September 1985, and penalties for violation were introduced in November 1986.

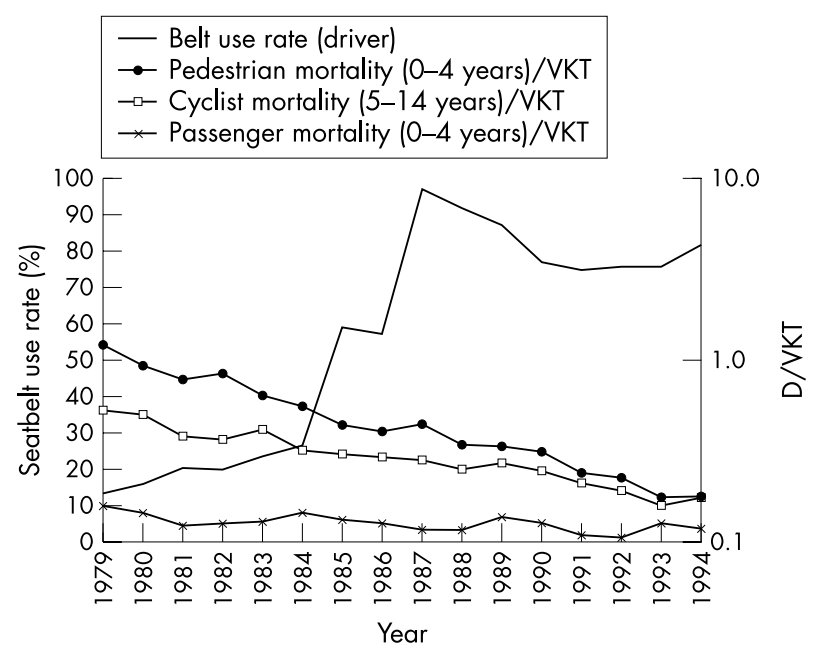

Figure 3 Seatbelt use rates in driver and child traffic mortality in Japan (1979-94). D/VKT, deaths per one billion vehicle km traveled. Child restraint law was enacted in April 2000

percentage change of seatbelt non-use rate showed a stronger correlation with the percentage change of D/VKT $(r=0.903$, $\mathrm{p}<0.001$ ) (fig 2).

Child pedestrian and cyclist mortality showed long term declining trends (fig 3) and did not clearly correlate with driver seatbelt use rates. Similarly, child passenger mortality did not correlate with driver seatbelt use rates.

\section{DISCUSSION}

This study suggests that increases in driving (VKT) may have masked any benefits of seatbelt legislation in Japan, since driver deaths showed a larger reduction than did the absolute number of driver deaths after legislation. Supporting this explanation is the fact that there was a rapid increase in traffic volume during the late 1980s in Japan. ${ }^{21}$ More driving exposes drivers and passengers to a greater risk of car crashes, either as a result of the increased number of cars or the longer distances traveled.

In countries where the increase in exposure to risk from driving equaled or exceeded the impact of seatbelt legislation, comparing the number of deaths before and after legislation could underestimate its benefits. Adams indicated that countries with seatbelt legislation showed slower mortality reduction than those without legislation. ${ }^{6}$ And other data from the United Kingdom showed little association between belt use 
rates and driver mortality, ${ }^{5}$ but this was probably attributable to a rapid increase in traffic volume.22 A rapid increase of VKT in countries with seatbelt laws might obscure the law's effectiveness; conversely, increasing traffic crash rates could have prompted the law's enactment.

After adjustment for increased traffic volume, the decrease of $\mathrm{D} / \mathrm{VKT}$ in Japan was less than the maximum expected reduction, based on the estimation that proper belt use would lower crash mortality by $40 \%^{1}$ and assuming that all drivers had an equal risk of crashing. Therefore, additional explanations, such as selective recruitment, must be considered.

In the present study, the percentage change in seatbelt non-use rate showed a stronger correlation with D/VKT change than either the percentage change in belt use rate or the annual percentage point difference in belt use. We conclude, therefore, that driver mortality was more responsive to changes in the behavior of less compliant drivers than those of the general public. This supports the theory that less compliant drivers are at higher risk of crashing (selective recruitment).

If all drivers had the same risk of crashing, the same percentage point increase of seatbelt use should lead to the same reduction in mortality, regardless of the seatbelt use rate. Therefore, the annual percentage point difference in seatbelt use would show the strongest correlation with driver D/VKT in the present study. Our results are consistent with those of Latimer and Lave who found that the higher the belt use rate, the more deaths were averted by the same percentage point increase of belt use. ${ }^{12}$ This suggests that when the seatbelt use rate is higher, the increase in belt use may result from behavior change among riskier drivers.

Seatbelt use rates among fatally injured drivers in vehicle crashes were disproportionately low compared with belt use among the general public. This is also in line with the selective recruitment theory. In Japan, during 1999, only 31\% of fatally injured drivers under 30 and $41 \%$ of those over 30 years used seatbelts whereas observed belt use in the general public was $88 \%{ }^{23}$ Attributing this discrepancy solely to the effectiveness of seatbelts in preventing deaths requires an assumption of unrealistically high belt performance. However, a study in the United States indicated that the assumption of a higher risk of crashing among non-belted drivers provided a better fit between the model and data. ${ }^{24}$

Less compliant drivers tend to be young, male, speeders, drinkers, and drunk drivers ${ }^{2112325-29}$; these are all traits that increase the risk of crashing. As the rise in belt use rate after seatbelt legislation may have occurred mainly among low risk drivers, the expected mortality reduction would not be achieved if unbelted high risk drivers accounted for most driver deaths.

Our study found no evidence of risk compensation affecting other road users. We might have underestimated the risk compensation effects involving pedestrians and cyclists because their exposure to traffic was reduced as car travel became more popular. ${ }^{22}$ However, risk compensation effects were not obvious even among child passengers who were also unprotected road users but increasing exposure. The seatbelt legislation did not directly protect child passengers. The child restraint law in Japan was only enacted in 2000 and the use of child restraints was rare before then..$^{30}$

\section{Limitations}

This study did not consider improper belt use or improved vehicle design, both of which may have modified seatbelt effectiveness. But there is no reason to assume that these factors affected seatbelt users and non-users differently. Changes in crash types, such as high speed crashes or drunk driving, may also have modified effectiveness. Although fatal crashes due to speeding were increasing, those due to drunk driving were decreasing. Consequently, the total number did not significantly alter.

\section{Key points}

- Most previous evaluations of seatbelt legislation have failed to identify the expected maximum mortality reduction.

- Possible explanations for this phenomenon include risk compensation, selective recruitment, and the rapid increase of traffic volume.

- Driver deaths per vehicle $\mathrm{km}$ traveled (D/VKT) showed a larger reduction than the absolute number of deaths.

- Drivers who are less compliant with seatbelt legislation may have a higher risk of car crashes, since mortality reduction was strongly correlated with decreases in the rate of seatbelt non-use.

- No increase in mortality was evident among road users not protected by the legislation.

In addition, there were biases in the data on belt use rates and VKT, since drivers are more likely to wear seatbelts during traffic safety campaigns and VKT data are based on drivers' self reports. However, the magnitude of these trends would probably have been similar between years.

\section{IMPLICATIONS FOR PREVENTION}

Non-seatbelt users, who increase the risk to themselves and other road users, should be targeted for safety promotion. To achieve greater effectiveness of seatbelt legislation, extremely high seatbelt use rates should be aimed for by bringing about behavioral changes among high risk drivers or introducing more passive forms of protection, such as automatic seatbelts.

\section{Authors' affiliations}

S Nakahara, M Ichikawa, S Wakai, Department of International Community Health, Graduate School of Medicine, University of Tokyo, Tokyo, Japan

\section{REFERENCES}

1 Evans L. The effectiveness of safety belts in preventing fatalities. Accid Anal Prev 1986;18:229-41.

2 Evans L. Safety-belt effectiveness: the influence of crash severity and selective recruitment. Accid Anal Prev 1996;28:423-33.

3 O'Neill B. Seat belt use laws in the United States: trends and prospects. Bull N Y Acad Med 1988:64:729-41.

4 Evans WN, Graham JD. Risk reduction or risk compensation-the case of mandatory safety-belt use laws. Journal of Risk and Uncertainty $1991 ; 4: 61-73$

5 McCarthy M. The benefit of seat belt legislation in the United Kingdom. J Epidemiol Community Health 1989;43:218-22.

6 Adams JGU. Risk London: UCL Press, 1995.

7 Loeb PD. The effectiveness of seat belt legislation in reducing driver-involved injury rates in Maryland. Transportation Research Part $E$ 2001;37:297-310

$2001 ; 37: 297-310$.
8 Rock SM. Impact of the Illinois seat belt use law on accidents, deaths, and injuries. Evaluation Review 1992;16:491-507.

9 Richens J, Imrie J, Copas A. Condoms and seat belts: the parallels and the lessons. Lancet 2000;355:400-3.

10 Evans L. Human behavior feedback and traffic safety. Human Factors 1985;27:555-76

11 Dee TS. Reconsidering the effects of seat belt laws and their enforcement status. Accid Anal Prev 1998;30:1-10.

12 Latimer EA, Lave LB. Initial effects of the New York State auto safety belt law. Am J Public Health 1987;77:183-6.

13 Petrucelli E. Seat belt laws: the New York experience-preliminary data and some observations. J Trauma 1987;27:706-10.

14 MacKay M. Seat belt legislation in Britain. J Trauma 1987;27:759-62.

15 Hayes HRM. Seat belt law: the United Kingdom experience. Bull NY Acad Med 1988;64:721-8.

16 Chorba TL, Reinfurt D, Hulka BS. Efficacy of mandatory seat-belt use legislation. The North Carolina experience from 1983 through 1987. JAMA 1988:260:3593-7.

17 Barancik JI, Kramer CF, Thode HC Jr, et al. Efficacy of the New York State seat belt law: preliminary assessment of occurrence and severity. Bull N Y Acad Med 1988;64:742-9.

18 Houston DJ, Richardson LE Jr, Neeley GW. Mandatory seat belt laws in the states. A study of fatal and severe occupant injuries. Evaluation Review 1996:20:146-59.

19 Robertson LS. Reducing death on the road: the effects of minimum safety standards, publicized crash tests, seat belts and alcohol. Am J Public Health 1996;86:31-4 
20 Garbacz C. Impact of the New Zealand seat belt law. Economic Inquiry Inq 1991;29:310-16.

21 Management and Coordination Agency. White paper on traffic safety in Japan 2000. Tokyo: The Agency, 2000 [in Japanese].

22 Roberts I. Why have child pedestrian death rates fallen? BM 1993;306: 1737-9.

23 Institute for Traffic Accident Research and Data Analysis. Traffic statistics 2000. Tokyo: The Institute, 1999.

24 Salzberg P, Yamada A, Saibel C, et al. Predicting seat belt use in fatal motor vehicle crashes from observation surveys of belt use. Accid Anal Prev 2002:34:139-48.

25 Nelson DE, Bollen J, Kresnow M. Trends in safety belt use by demographic and by type of state safety belt law, 1987 through 1993 Am J Public Health 1998;88:245-9
26 Lerner EB, Jehle DVK, Billittier IV AJ, et al. The influence of demographic factors on seatbelt use by adults injured in motor vehicle crashes. Accid Anal Prev 2001;33:659-62.

27 Preusser DF, Lund AK, Williams AF, et al. Belt use by high-risk drivers before and after New York's seat belt use law. Accid Anal Prev $1988 ; 20: 245-50$

28 Foss RD, Beirness DJ, Sprattler K. Seat belt use among drinking drivers in Minnesota. Am J Public Health 1994;84:1732-7.

29 Sahai VS, Pitblado JR, Bota GW, et al. Factors associated with seat belt use: an evaluation from the Ontario Health Survey. Can J Public Health 1998;89:320-4.

30 Japan Automobile Federation. Trend of child restraint use rates [in Japanese]. Available from: http://www.jaf.or.jp/safety/index.htm.

\section{BOARD MEMBER BIOGRAPHY}

\section{Peter Lundqvist}

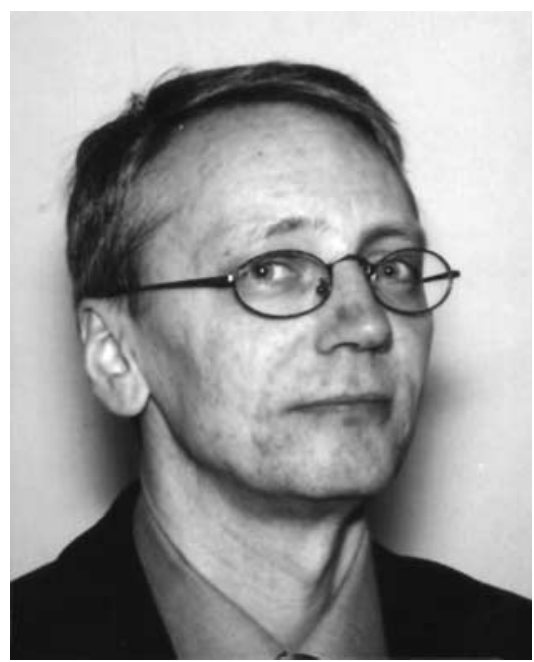

r Peter Lundqvist is a Professor of Work Science at the Department of Agricultural Biosysems and Technology at the Swedish University of Agricultural Sciences. He is located at a campus in Alnarp in the very south of Sweden.

Peter got his BSc from Lund University 1981 and has worked since then at the Swedish University of Agricultural Sciences (SLU) on the human aspects of farming and other rural work. In 1988 he presented his dissertation "Working Environment in Farm Buildings" and received his PhD at SLU. Since 1999 he has been the first Professor in Work Science within the Faculty of Agriculture. Peter is the head of the Division of Work Science and active in both teaching and research.

Some examples of current projects involves: traffic accidents with slow moving vehicles, prevention of child accidents, large scale animal production-management, injuries, and ergonomical aspects. He is also leading a European Union project on lifelong learning along the food chain.

Peter has a big interest in the transformation process within the agricultural and rural sectors and its effect on working conditions, such as changes in animal welfare regulations and the introduction of organic farming or new technologies, such as milking robots. Other issues involve transformation from family farms to large scale farming, the increasing use of migrant workers, and the integration of immigrants into agricultural work. Peter's opinion is that researchers in injury prevention have to be involved in the transformation process in order to achieve positive results in the future. 